Portland State University

PDXScholar

5-15-1997

\title{
Combining the Historical and the Personal in Painting
}

Christopher A. Shotola-Hardt

Portland State University

Follow this and additional works at: https://pdxscholar.library.pdx.edu/open_access_etds

Part of the History of Art, Architecture, and Archaeology Commons, Interdisciplinary Arts and Media Commons, and the Painting Commons

Let us know how access to this document benefits you.

\section{Recommended Citation}

Shotola-Hardt, Christopher A., "Combining the Historical and the Personal in Painting" (1997).

Dissertations and Theses. Paper 5393.

https://doi.org/10.15760/etd.7260

This Thesis is brought to you for free and open access. It has been accepted for inclusion in Dissertations and Theses by an authorized administrator of PDXScholar. Please contact us if we can make this document more accessible: pdxscholar@pdx.edu. 


\section{THESIS APPROVAL}

The abstract and thesis of Christopher A. Shotola-Hardt for the Master of Fine Arts in Art: Painting were presented May 15, 1997, and accepted by the thesis committee and the department.

COMMITTEE APPROVALS:

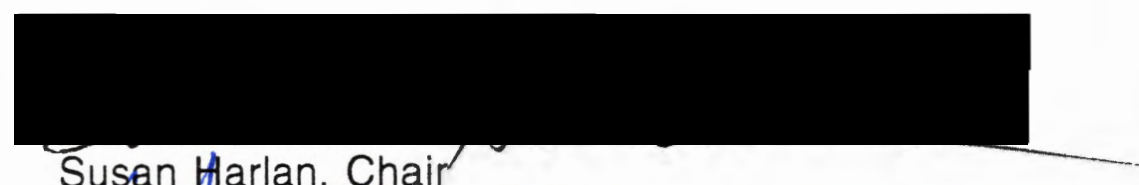

Susan Harlan, Chair
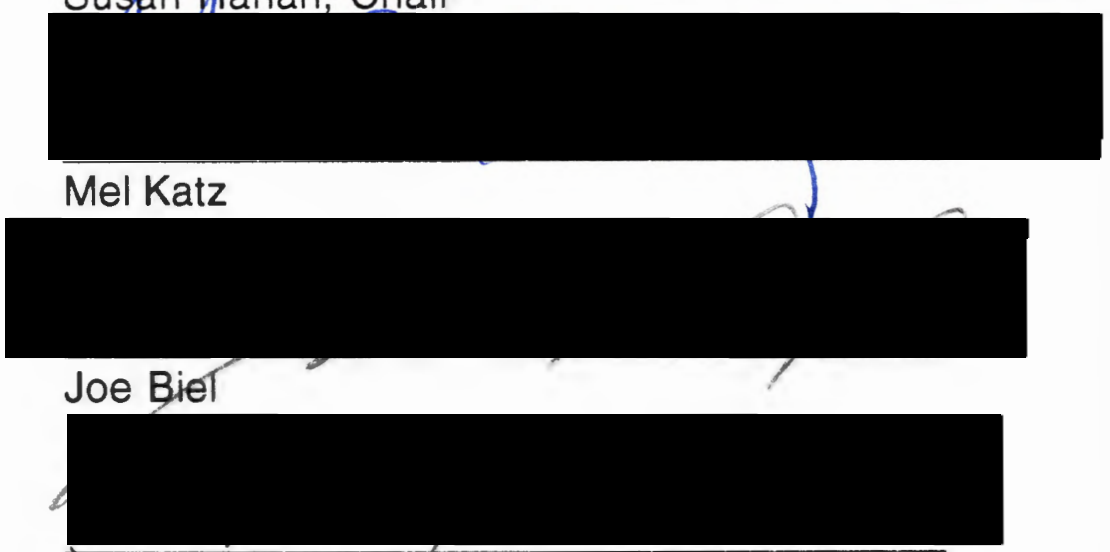

Harry Widman

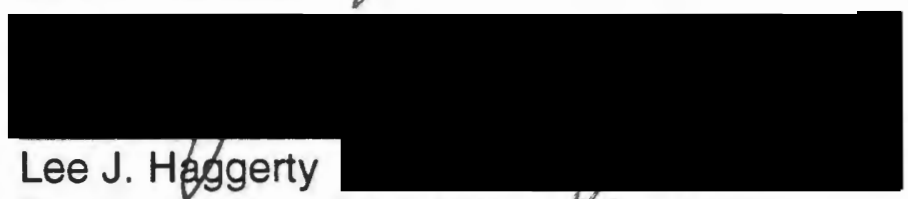

Representative of the Office of Graduate Studies

DEPARTMENTAL APPROVAL:

Mary Constans, Chair

Department of Art

\section{ACCEPTED FOR PORTLAND STATE UNIVERSITY BY THE, LIBRARY}

by on

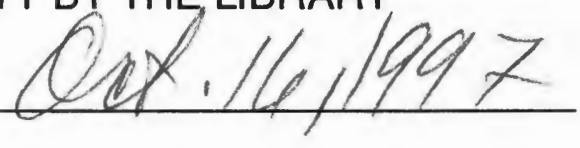




\section{ABSTRACT}

An abstract of the thesis of Christopher A. Shotola-Hardt for the Master of Fine Arts in Art: Painting presented May 15, 1997.

Title: Combining the Historical and the Personal in Painting.

This thesis project consists of five large scale, abstract paintings executed on Masonite panels. A major component of these paintings is the heavily built-up surface texture. In order to achieve this heavy, sculptural surface, plaster and acrylic media have been applied in an aggressive, spontaneous manner using variously-sized masonry knives. The paintings are largely action-oriented. They are non-neutral, and they bespeak a great deal of intensity on the part of the artist.

The five paintings contain emotional content based upon personal experiences and family history. In some cases, I began a painting with the subject matter clearly in mind. In other cases, the subject matter began to make itself known during the process of painting, or afterward, when I spent more time with the work, studying its gestures, surface and energy, and reflecting on the events surrounding its creation. The titles are important, and they always come after the work is complete. They offer possible entries into the meaning of the work. Of course, if the viewer perceives any meaning at all, it is a result of his or her own mental processes. I have no control over that. What I have tried to do in these paintings is imbue them with enough strength that they might confront the viewer and evoke an exchange of experience. 
COMBINING THE HISTORICAL AND THE PERSONAL

IN PAINTING

by

CHRISTOPHER A. SHOTOLA-HARDT

A thesis submitted in partial fulfillment of the requirements for the degree of

\section{MASTER OF FINE ARTS}

in

ART: PAINTING

Portland State University

1997 


\section{Table of Contents}

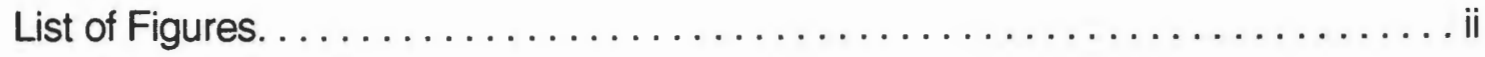

Part One: Introduction. .....................................

Part Two: Formal Concems ............................ 4

I. Scale. .................................... 4

II. Materials, Methods and Sculptural Tendencies. . . . . . . . . . . . 5

III. Spatial Effects. . . . . . . . . . . . . . . . . . . . . . 8

Part Three: Context and Interpretation. . . . . . . . . . . . . . . . 11

Part Four: Conclusion. . . . . . . . . . . . . . . . . . . . . . . . . . . . . 19

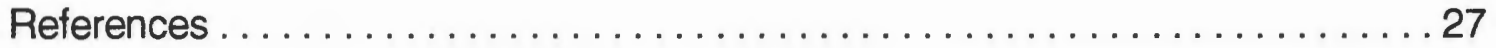




\section{List of Figures}

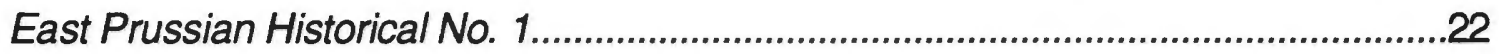

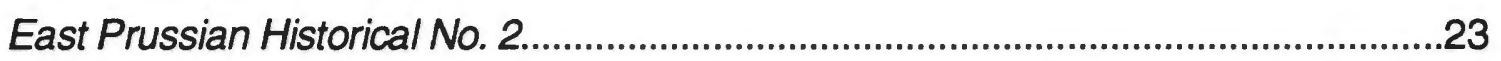

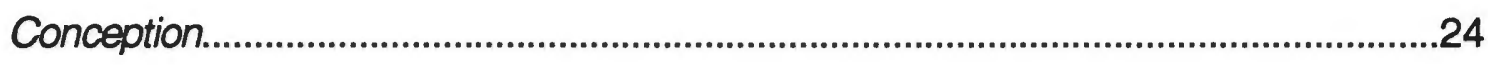

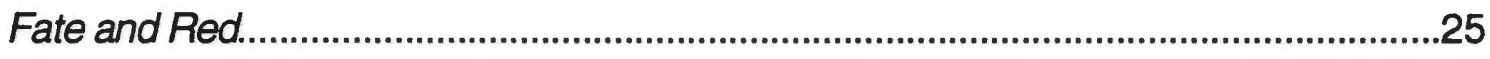

Guardian 


\section{Part One:}

\section{Introduction}

Painting, for me, is a way to respond to my experiences, and I have always drawn from my experiences in making paintings. I have always had this need to react to things in a creative format, whether it be through music, poetry or painting. It is interesting to note that, for me, these art forms have certain things in common: they belong to the domain of the brain's right hemisphere and the unconscious, they offer great potential for expression and nuance, and they provide a means of responding to an experience with an experience (the creative process) as well as -- when a piece is finished -- a means of offering an experience to others (the listening, the reading, the viewing).

The art I have always been most interested in is that which deals with life, moods, experiences, feelings and convictions. I seek art that grapples with finding meaning and significance in human experience, casts critical commentary, stimulates new ways of thinking about something, or takes me someplace I haven't been before. The art should have its own power and evoke in me an exchange of experience. I have no interest in something that tries hard to be smart or clever. It has to be honest, internal, personal.

This is what I expect from my art as well. I know I have succeeded if the surface and gestures are not forced, but are allowed to happen. My marks initially may not be in a manner that works in a formal sense, but I can keep working it. I need to be alert to my present condition, my state of mind, how my body feels, what is happening in my life, and so on.

Everything I do creatively draws from my experiences -- things that actually happen to me personally or, for example, what I experience reading a book. The five paintings that comprise this thesis exhibition -- Fate and Red, 
Guardian, East Prussian Historical No. 1, East Prussian Historical No. 2, and Conception -- each have their own stories.

I am a process artist. In both natural and urban settings, I am fascinated and inspired by surfaces and textures that have evolved naturally or have been altered through natural erosion or intermittent human influences. It is the unconscious act or process that interests me -- a series of events are recorded and this "history" remains in the surface. I try to approach my work in the same way. I try not to direct my paintings toward predetermined ends, but rather to allow my unconscious free reign. I start with the first mark, respond to it with the second, the third, and so on. The painting evolves and I evolve with it. I rely on chance. Accidents lead to opportunities. Earlier details may be scraped away or covered. Layers build up in my work. Several paintings may exist beneath the final work, and although they may be more or less covered up, traces of them still linger in the surface.

My embracing of the unconscious and the basic tenor of my paintings -abstract, aggressive, spontaneous, intense, emotional -- put my work in a position sympathetic to abstract expressionism. Expressionism is a way of making art that is opposed to all theories, because it places the primary stress not on system or theory, but on the spontaneous expression of feeling. ${ }^{1}$ While expressionist movements have flourished on both sides of the Atlantic, I feel a stronger kinship with certain European artists (who aren't necessarily wholly defined as abstract expressionists) than with anyone associated with the New York School. Anselm Kiefer, Emil Schumacher and Antoni Tapies have had great influence on me. I share their interest in heavy-handed surface-making, mixing various materials with the pigments to achieve a certain level of

'Lucie-Smith, Edward, Art Today (London: Phaidon Press Limited, 1995), p. 173. 
relief and varied surface effects. Their work is rich with surface history. Schumacher and Tapies align themselves with the Buddhist idea that one should visit sites of destruction in order to gain valuable themes for contemplation, and their work, along with Kiefer's, bespeaks an aesthetic exhibiting a destructive nature.

I also share these artists' interest in combining the historical and the personal within the work. Schumacher and Kiefer produce emotionally potent work which deals, in part, with personal issues in the context of postwar Germany. Both are critical of the nationalistic tendencies that helped usher in the events of the second world war. Tapies' context is that of the Franco regime in Spain. He also deals with a myriad of issues, including the loss of cultural identity through oppression.

The five paintings in this thesis exhibition combine the personal and the historical. As I have come to understand, the paintings are personal, emotional responses to my life experiences. They occur in the context of the history I have lived through -- where all the previous moments of my life come to a head and affect my present, personal response -- as well as the history my family has lived through which has had a bearing on the kind of person I have become. 


\section{Part Two:}

\section{Formal Concerns}

All five of the works in this thesis exhibition are paintings on Masonite. Although the mark making and the handling of materials vary from piece to piece, certain formal ideas underlying the paintings remain constant and help to hold the pieces together as a body of work. Here I will outline these ideas and describe how they are employed in the work. Part Three will include a discussion of the content of the work.

\section{Scale}

The basic unit I use in each of these pieces is a four by six foot sheet of untempered Masonite mounted upon a frame of either MDF or pine. I have chosen these dimensions because of their relation to human scale and because I wanted the surfaces to be large enough to accommodate full-arm gestures. I feel that when I am able to involve my whole body in the process of painting, the marks will reflect my particular physical stature and characteristic movements.

I use the four by six foot panel units in different combinations for works of varying scale. In all cases, the panels are positioned vertically, although not all of the finished paintings have a vertical orientation. Two of the works, Fate and Red and Guardian, use only single panels. East Prussian Historical No. 2 and Conception are four by eight foot diptychs. East Prussian Historical No. 1 is a four by twelve foot triptych. The reason I have chosen to work with the diptych and triptych -- as opposed to painting on single panels having the desired total dimensions -- is a purely practical one. During the painting process, I shift the panels back and forth between three different positions: flat on the floor, 
leaning against the wall, and hanging on the wall. Because I use so much plaster and build the surfaces up to such an extent, the panels can weigh a tremendous amount; trying to shift a single panel with the full dimensions of the diptychs or the triptych back and forth between these three positions would prove impossible for me. Two further factors in my decision concern the storage and transportation of the work.

In the diptychs and the triptych that appear in this exhibition, I have ignored the line which marks the boundary between one panel and the next; there is nothing in any of these compositions that acknowledges the presence of these lines. (In other concurrent works, which were not included in the exhibition, I do acknowledge the line between separate panels.) Here my intention was not so much to use a diptych or triptych format as to execute works of substantial scale. Works of such large scale can more easily envelope the viewer and potentially have a stronger impact by absorbing the viewer into the world of the painting.

\section{Materials, Methods and Sculptural Tendencies}

Acrylics, latex enamel house paints, acrylic media (gel medium, sculpting gel, Aquavar) and plaster are the materials I have used for these five works. The paintings were executed on gessoed Masonite. Guardian and Fate and Red were painted on the smooth side of the Masonite, while the three larger works were painted on the rough side. This rough side provided adequate tooth for the plaster to adhere to, and these larger pieces use much greater amounts of this material. The rough texture has a "woven" pattern like canvas, and in these three larger pieces I allowed areas of this plain, gessoed "canvas" to 
show through and contrast with areas of high, textured relief.

I use variously-sized masonry knives and palette knives in applying the plaster and gel medium. I alternate between knives and brushes when applying the paint or the other acrylic media. Most of the surfaces are worked in a wet on wet, alla prima manner. The work done in one session usually comprises an integrated, closed system; it will have dried by the time the next session begins, and that can make it more difficult to integrate new materials into the surface.

While painting Guardian, I was able to integrate follow-up layers into the under layers by scraping down areas of the painting and filling in the space with new material. In other portions of the painting I completely covered the under layers with new plaster applications. Because these new applications, like the older ones, were all being colored by multiple layers of burnt umber wash, new systems integrated well with older systems. Guardian is a predominantly monochromatic piece, with only a few traces of a layer of red underpainting and a layer of slate-colored under painting showing beneath the complex surface near what many people have interpreted as a human figure (the four shapes whose value is much lighter than the painting's ground). The burnt umber has been applied both as straight pigment and as wash to the built-up plaster surface. It has also been darkened in places with varying amounts of black. I wanted a rich surface with subtly shifting tones to enhance the surface effect. In the four lighter shapes, wash was applied and then wiped down, leaving a residue in the crevices that accentuate the texture. The slow, additive process used to create the surface contributes to the more controlled appearance of this piece.

Fate and Red also employs heavily textured plaster. Here it is infused with varying amounts of black pigment and recalls a wall. The base surface of 
this wall alternates in color between medium and light charcoal and an even lighter ashen white. Dark drips cover the majority of the wall surface and provide a weeping quality -- or perhaps a tormented, destructive quality. In many places, the dark drips also help the eye to sort out subtle shifts in value seen on the wall surface and this adds to the richness and depth of the surface treatment.

Countering the darkness of the plaster in Fate and Red is the left hand one-third of the panel where I painted red in hurried vertical gestures. I then partially washed the red away by pouring water over it; this caused the red at the bottom of the left side to gradually fade from view, and also exposed an area running vertically through the center of the red that earlier had been scraped down below the plaster to a smooth, glassy finish.

This glassy finish appears elsewhere in the painting: within the two small red shapes just to the right of the center of the panel, and throughout the bottom one-third and along the right vertical edge of the panel. Here, glimpses of a scraped-down yellow, sienna, unbleached titanium and umber underpainting show through gaps in the dark wall surface, which appears to be breaking apart. This under layer comprised a closed system over which the plaster was applied. The smooth, glassy surface offers another counterpoint to the dark, physical surface of the wall.

All five of the paintings include areas of heavily-applied plaster, which introduces a sculptural element to the pieces. These physically assertive areas are really in low relief. Their physicality is supported by the thickness of the panel frames, which range from two to four inches in depth, depending on the piece, and make the paintings more object-like. 


\section{Spatial Effects}

A common counterpoint to the physicality of the plastered areas of these works is a thin, washy paint that sometimes allows the texture of the Masonite to showthrough. Sometimes this wash can have an atmospheric quality, and in such cases I utilize this to create a sense of spatial depth.

In East Prussian Historical No. 1, the black arch form assumes a containment role in the painting, helping to establish a space within which we can make sense of the rest of the painting. In some places, on the far right bottom side, for instance, the black line comes over the gray plaster shapes, pushing the gray shapes back in space. Behind the gray shapes is a space created by the application of a thin wash of unbleached titanium and red oxide. Throughout the three panels I continually use this alternation between thin, washy paint and built up, textural plaster in order to create a sense of space. The gray plaster forms are positioned not only behind the black arch, they also cross over the central portion of the arch, giving the illusion that these shapes occupy different vertical planes in the middle and background. The use of paint drips serves a similar function: in places the drips pass over a plaster shape while elsewhere the drips appear to pass behind the plaster. In all cases, the drips pass in front of the areas of wash. The wash in many places (especially in the top and bottom middle section and on the right side) includes an unbleached titanium which gives the effect that there is a light source in the background and enhances the sense of spatial depth.

In East Prussian Historical No. 2 as well, a sense of space is created by the fluctuation between heavily-textured surface and thin paint application. The space into which the eye can move back is the bare gessoed surface in the lower mid-sections of each of the panels. This space became visible after I 
washed away paint and debris by pouring buckets of water over the surface. The heavily built-up texture channeled the flowing water and influenced the vertical, downward movement; remnants of debris and traces of thinned yellow paint form vertical stripes, between which we see the bare gesso. In the upper left corner of the diptych heavy paint and plaster applications are situated in front of an area of wash. This occurs as well along the right and left edges of the painting. Along these edges and at the bottom, paint drips were allowed to run diagonally in front of the wash; these diagonals cut behind the vertical movement of the debris and some of the brushed gestures.

The spatial effect in Conception is a little different. Across the two panels of the diptych, there is the varying interplay between a pastel pink paint and a textural plaster mixed with black pigment. The black and the pink are engaged in an interesting push and pull in the space. Bright, warm colors normally tend to come forward, while dark, cool colors tend to sink back. Here I have applied the pink most often as a background wash, which in this case gives it a spatial or atmospheric reference. The dark plaster is very chunky and textural. The pink is trying to come forward while the dark plaster is trying to fall back. Because of its shear physicality and the fact that it has been applied over the pink, the plaster minimizes the pink's coming forward. This oddity creates a compressed visual plane. Adding to the strange effect are the pink drips in the upper right corner of the diptych cascading over the heavily textured plaster.

In Fate and Red, the yellow and umber under painting definitely assumes position in the background since the plaster has visibly been applied over it and the dark drips have run freely in front of it. The under painting creates a subtle spatial effect, lending vastitude to an otherwise frontal work. Seen at a distance, the red comes forward and appears to float above the dark wall surface. 
Spatial effects have been important elements in my work during the two years of the graduate program. It is partly my use of illusionistic space which separates my work from abstract expressionism, concerned with maintaining the integrity of the flat picture plane. It is the sense of space which drives many of my paintings and which alludes to the physical world. The space helps create a sense of place, as is evident in the two East Prussian Historical works. By alluding to the world in this way, the space here strengthens the emotional, historical and visual impact of the paintings (there is a space the viewer can enter visually where an "event" has occurred). 
Part Three:

Context and Interpretation

I begin some paintings with the subject matter clearly in mind. In other paintings, the subject begins to make itself known during the process of painting, or sometimes afterwards, while I spend more time with the works, studying their gestures, surface and energy, and reflecting on the events surrounding their creation. The titles always come after the work is complete, when I have a strong idea of the content of the work. I feel titles are very important, offering possible entries into the meaning of the work. My titles are never straightforward; they merely hint at my mental framework. I choose to paint in an abstract manner because of the openness and the opportunity to view the work differently at different times (also because this style of painting allows me to express feelings that are difficult to put into words). My titles should have the same openness.

My family background has had a profound effect on who I am. Strong influences arose from both my mother's side and my father's side of the family. East Prussian Historical No. 1 and East Prussian Historical No. 2 are paintings that deal with my father's family history.

My father is an immigrant from East Prussia, a one-time German state situated between Poland and Lithuania on the Baltic Sea. I grew up hearing stories of living in East Prussia as well as stories of leaving East Prussia. Sometimes I feel it is the stories of the loss and the leaving that have had the greatest impact. Certain impressions from these stories have had a lasting effect 
on me and are at the core of these two paintings. ${ }^{2}$

Following World War II, the southern part of East Prussia was annexed to Poland, while the northernmost strip -- where my father and his family lived -was occupied and later given to the Soviet Union, which wanted a strategic link to the Baltic Sea as well as the fertile farmland. Until quite recently, this heavily militarized Soviet zone was off-limits to visitors.

In 1994, my father traveled with two of his cousins back to his hometown Tilsit for the first time since their evacuation. He wrote a long and very moving account of his journey. East Prussian Historical No. 1 was painted upon the occasion of one of several readings of my father's travel journal. Whether or not the viewer knows the circumstances under which I painted this piece, he or she may be able to sense strong emotional content. There is a feeling of destruction evident in the broken, dripping black line which forms the arch; also, the gray plaster shapes throughout the piece have the color and texture of concrete and appear as though they are breaking apart. Adding further to the feeling are the paint drips which have a weeping quality and have not been controlled. The white splash is spontaneous and uncalculated, as is the light gray form on top of it.

This light gray plaster form in front of the white splash is crucial to the content of the work. It is located at head level and near dead-center of the triptych. The white behind it is in motion, as are many of the other elements in

\footnotetext{
2 While my grandparents were still alive, I sensed in them a feeling of longing for another place. I heard discussions and musings about what might have been, and understood the realization that on a core level America, for them, was not home. This was not where all of our ancestors had lived.

My grandparents were refugees. I felt especially close to them and realize their great influence on me. I studied the German language and German history and culture throughout my schooling and even spent three semesters studying theology and Germanistik at Universität München. Throughout my life I have made several trips to Germany and the former East Germany in order to visit extended family members, and many of those family members have made numerous trips to the States. I have not yet visited regions of the former East Prussia.
} 
the background, but this gray form is stationery, hovering. It is a subtle element. Its color and texture are similar to the other gray plaster shapes. One must look closely in order to see it and differentiate it. This light gray form should raise questions, should be an unknown, an uncertainty. It symbolizes for me the unknowns of my family heritage, all of the "what ifs."

Within the context of this work's creation, namely my reflections concerning my father's travel journal, the unknown is what my father experienced while he visited his family farm. While he expressed the power of his experience in his journal, words cannot fully convey the strength and intensity of such a journey. East Prussian Historical No. 1 was inspired by my imagining what that physical and emotional journey must have been like.

East Prussian Historical No. 2 is a diptych which also deals with my father's family history. This piece is not a response to the aforementioned travel journal. It stems, rather, from lifelong emotions and thoughts, questions and frustrations. I carry with me a flood of images, stories and impressions concerning this history. I have been fascinated with reading historical documents and have heard first-hand accounts from a great number of individuals. Despite my investigations, however, I am ultimately faced with the impossibility of my ever knowing what it was really like to have experienced all that befell my father's family during the war and in the aftermath. Yet I do know that these events have had a profound effect on me, and certainly on how I was raised.

Shortly after painting East Prussian Historical No. 1, I received a rather timely piece of mail from an uncle who shares my great interest in our family's history. The article Uncle Fritz translated and sent me and a subsequent 
conversation with my father provoked strong emotions and reflections around many issues. I was consumed by these when I painted East Prussian Historical No. 2. The painting provided a means of responding to these wartime experiences and expressing emotions that are difficult to put into words. As in No. 1, the viewer will not know the stories or circumstances surrounding this work's creation, but a strong emotional content may be evident. The title, too, will help steer the viewer, especially if he or she knows something of East Prussia or at least knows that it no longer exists. The word "historical" in the title coupled with the aggressive surface and the grayish palette ought to bespeak a certain amount of intensity.

That I should be interested in dealing with family history in my work is nothing new nor by any means finished. Much of my work during the first year of graduate school centered around these matters. Given my keen interest in children's picture book illustration, it was a challenge to find an appropriate voice that wasn't illustrative. The present paintings in my thesis exhibition are far more effective and true in conveying the feelings than anything I did during the first year, and these are but two of many more I anticipate.

East Prussian Historical No. 2 has certain elements in common with East Prussian Historical No. 1, and these commonalities should visually link the works together. The most important commonality is the aggressive, spontaneous, intense surface treatment. The space I talked about in Part Two and the vertical dripping comprise two more commonalities. Another is the black arch form. In No. 2, however, there is only a fragment of the arch, the middle section; the arch's posts exist beyond the left and right edges of the diptych. In No. 2, as in No. 1, the black painted line is broken in many places where there is a downward coursing of paint: some drips of black paint 
occurred during the full-arm gesture that defined the line; other interruptions in the line resulted from a downward scraping of a putty knife and from the water that was poured over the surface. In both paintings, the black line also helps to determine the compositional organization.

Yet another commonality is debris. No. 1 has plaster forms that resemble concrete and have a destructive appearance. No. 2 has actual debris strewn across the entire surface: scrapings, chunks, shards, muck and gravel-like material collected from the floor of my studio. Much of this material was mixed in with the applications of plaster and paint and became integrated into the surface, but other pieces appear to be loose and suspended on top of the surface. The use of this debris helps to create the climate of Angst.

Angst is evident as well in the action-oriented gestures in both of the works: the white splash across the front of No. 1 and the drips; the chaotic, weighty gestures above the black arch in No. 2 and how they seem to cause the sagging of the black line and the subsequent falling apart of what lies below the arch. These actions occurred in progress in the painting. We cannot see how they might resolve.

Two paintings from the fall of 1996, Fate and Red and Guardian were painted shortly after my wife's and my experience of having to end an ectopic (tubal) pregnancy through chemo therapy. I have come to realize the impact that this experience had on my work and the titles of these pieces reflect my interpretation.

Fate and Red addresses that initial anguish. It is a brooding piece and offers up raw emotion. Guardian has a much quieter mood. The surface, with its color and manner of plaster application, might recall a natural rock wall 
formation. The allusion to a rock wall is intentional. I have titled this piece Guardian, in part, because of the abstract human figure. The " $y$ " shape is reminiscent of an armor piece worn to protect the upper torso of a soldier. The reference to the rock wall is another inspiration for the title. Rocks exist in geologic time, which is far broader than human time. This reminds me of the enduring quality of the Earth and Nature's ultimate resilience.

It is interesting to note that Conception was painted the weekend my wife and I found out we were again pregnant. It is an action painting in the fullest sense. It has the energy of an explosion, which is an accurate description of my mental and emotional state at the time. The news required a shift in paradigms, a blowing apart of prior frameworks.

The impression that an explosion has just happened, or is in the process of happening, is created by the manner of plaster application. One can perhaps imagine that the plaster was at one time part of a large single piece that now has broken apart. The epicenter of this event may have been the area of pink in the very center of the diptych, where the two panels join together. This pink is in the process of a slow, downward oozing. It draws the viewer's attention. It stands out among the other pink areas because of the white streaks which define its outer contours. The plaster to the immediate lower left of this pink area and the plaster to the upper right look as though they could fit back together like puzzle pieces. Other pieces of plaster nearby (to the lower right and beyond these in the lower right portion of the painting) were applied in quick gestures which drew the plaster through wet portions of pink paint; this gives the appearance of being in motion. These gestures, applied with a masonry knife, draw the material away from the center. 
This quick gesture of drawing plaster through the wet pink paint is repeated in various places across the piece. This is coupled with leaving some plaster intact as chunky, textured shapes. In many of the spaces between plaster shapes and gestures, I have deposited shards and pieces of plaster which had dried on the inside of my plaster-mixing bucket. These pieces became stuck in the wet paint surface. They look like suspended debris -smaller pieces blown off a previously existing form. Many of the larger, chunky plaster shapes (i.e., in both the upper left side and the upper right side of the painting) also appear suspended, but their outer contours become fuzzy as the pigment in the plaster mixed with the pink paint a little bit; this also produces an illusion of movement.

The sense of exploding lends the painting a feeling of chaos. One can perhaps imagine the action moving beyond the confines of the panels. Though the sense of composition is unusual, structurally, the painting holds together through repetition of certain kinds of devices. The drips occur in spots across the whole piece, as do the quick knife gestures. The larger plaster shapes are interspersed throughout the work amidst the pink paint. The pink paint plays the role of the ground, which also is seen throughout.

Ultimately, I have no control over how a painting will be viewed. As Dave Hickey wrote, "The meaning of a sign is the response to it." 3 William Stafford expressed a similar sentiment about poetry:

\footnotetext{
${ }^{3}$ Hickey, Dave, "Nothing Like the Son: On Robert Mappelthorpe's X Portfolio," The Invisible Dragon: Four Essays on Beauty (Los Angeles: Art issues. Press, 1993), p. 29.
} 
Any implications are in the mind of the reader. . I would like that to be not my enforcing something, but my presenting something from which they get something. . . The activity of the reader is the life of the poem. ${ }^{4}$

I feel the same way about painting. A title may suggest something of the context in which a piece was painted, or hint at my own interpretation, but any explanation I could offer is largely irrelevant. If the viewer perceives any meaning, then it is there. Interpretation is completely subjective, hinging entirely on the viewer's own mental processes and experience.

"Markee, Michael and Vincent Wixon, "William Stafford: The Life of the Poem," Contemporary Poets Series (Ashland, OR: TTTD Productions, 1992), video. 


\section{Part Four:}

\section{Conclusion}

I cannot dictate exactly how my work will be experienced by the viewer. By presenting such large pieces, ranging from human scale to mural size, and by having attacked the surfaces in an aggressive, spontaneous manner (particularly in the three larger pieces), I want to instill a certain power in the work. These paintings are not neutral. They bespeak a great deal of intensity. Entering the gallery space the viewer will have to confront them and bring her or his own mental and emotional frameworks into the experience.

While certain experiences and stories have been the driving forces behind these paintings, the paintings themselves do not tell stories. The fact that I am painting in an abstract manner leaves the work open to interpretation. Successive readings of these paintings for me can be just as varied as the viewers'. Certainly, as products of the unconscious, these paintings may be about other things that I am not aware of. What I have offered is my interpretation of these works at this time.

It is noteworthy, I think, to acknowledge the chronology of the works included in this show in clarifying how I see myself as a painter at this particular point in time. Fate and Red and Guardian were among several single panel pieces painted in the fall of 1996. While surface texture had long been a central feature of my work, this was the time in which I began to consistently build up a substantial surface relief with plaster and acrylic media. Because I was acquainting myself with new materials and tools, these first pieces in the fall were executed in a much more deliberate fashion than the more spontaneous diptychs and triptych; hence, they appear much more controlled. At that time I spent much time studying the surfaces of Dubuffet, Tapies and Schumacher, 
and I think their influence is apparent in the work (Guardian, for example, might recall the wall paintings of Tapies as well as the primitivistic "portraits" of Dubuffet).

East Prussian Historical No. 1 and East Prussian Historical No. 2 were painted in the winter of 1997 . They reflect my interest not only in German history but in German historical and landscape painting, specifically the work of Albrecht Altdorfer, Caspar David Friedrich, and Anselm Kiefer. These two paintings are "history" paintings; the allusion to debris and destruction in their surfaces coupled with the sense of place created by the illusion of space informs the viewer that an event has occurred here. I am not interested in the literal recording of an historical narrative, however. Rather, I'm interested in presenting grand, encompassing emotional statements with hooks into actual history and the world. Space, as I have indicated, is one such hook. The use of the black arch form in these works was intended as a reference to East Prussian architecture; it also references Emil Schumacher, who used the arch extensively throughout the seventies and eighties. Whereas Schumacher's paintings are rather wall-like and maintain a flat picture plane, I have set the arch into more of a space. These paintings, especially East Prussian Historical No. 1, have a landscape quality.

Conception was painted after the historical pieces in the late winter. There is less reference to other painters. I have abandoned illusionistic space altogether so that the painting does not refer to the world as do as the other works in the show; it is more internal. This painting is more about pure painting. It does not use a conscious organizational device like the arch or or like the central figure in Guardian. The mark-making is haphazard and chaotic, the tension in the work is not resolved. The rectangularity of the panels is hardly 
enough to contain the work, as the action in the piece threatens to spill into the room. The process of this action painting's creation is very much alive. The work raises questions and provides no answers. Perhaps this is problematic. Though viewing interest, I think, begins here with the lack of resolution.

At this point I am at a crossroads in my painting. During the graduate school experience I feel I have accomplished two major goals: I have defined my art historical lineage and I have developed a personal language in painting that I know will be a part of my work for some time. The main vocabulary includes physical, spontaneous gestures and heavily-textured surfaces. The East Prussian Historical pieces and Conception point in two possible directions for my work. I am not sure that I want to choose one over the other right now, nor do I feel there is any need to prefabricate my direction. Multiple directions are interesting and the potential for appropriation and crossfertilization intrigues me. This problem of how I straddle the historical and the personal, the references to the world and the expression of the internal, remains unresolved in my work. The unanswered questions will serve to push me further. While I seek to define what it is that I am doing, the not knowing is what drives me. 


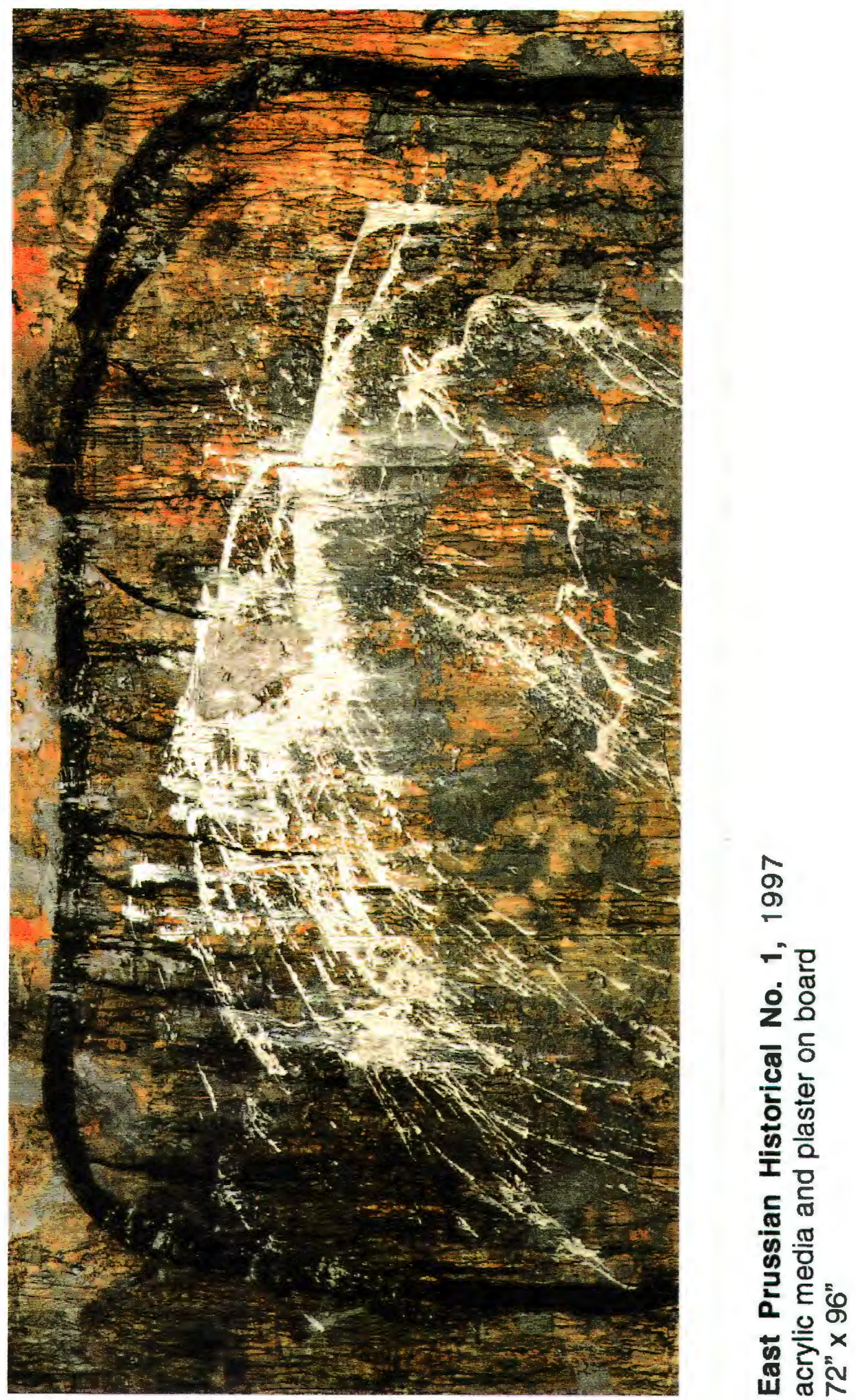




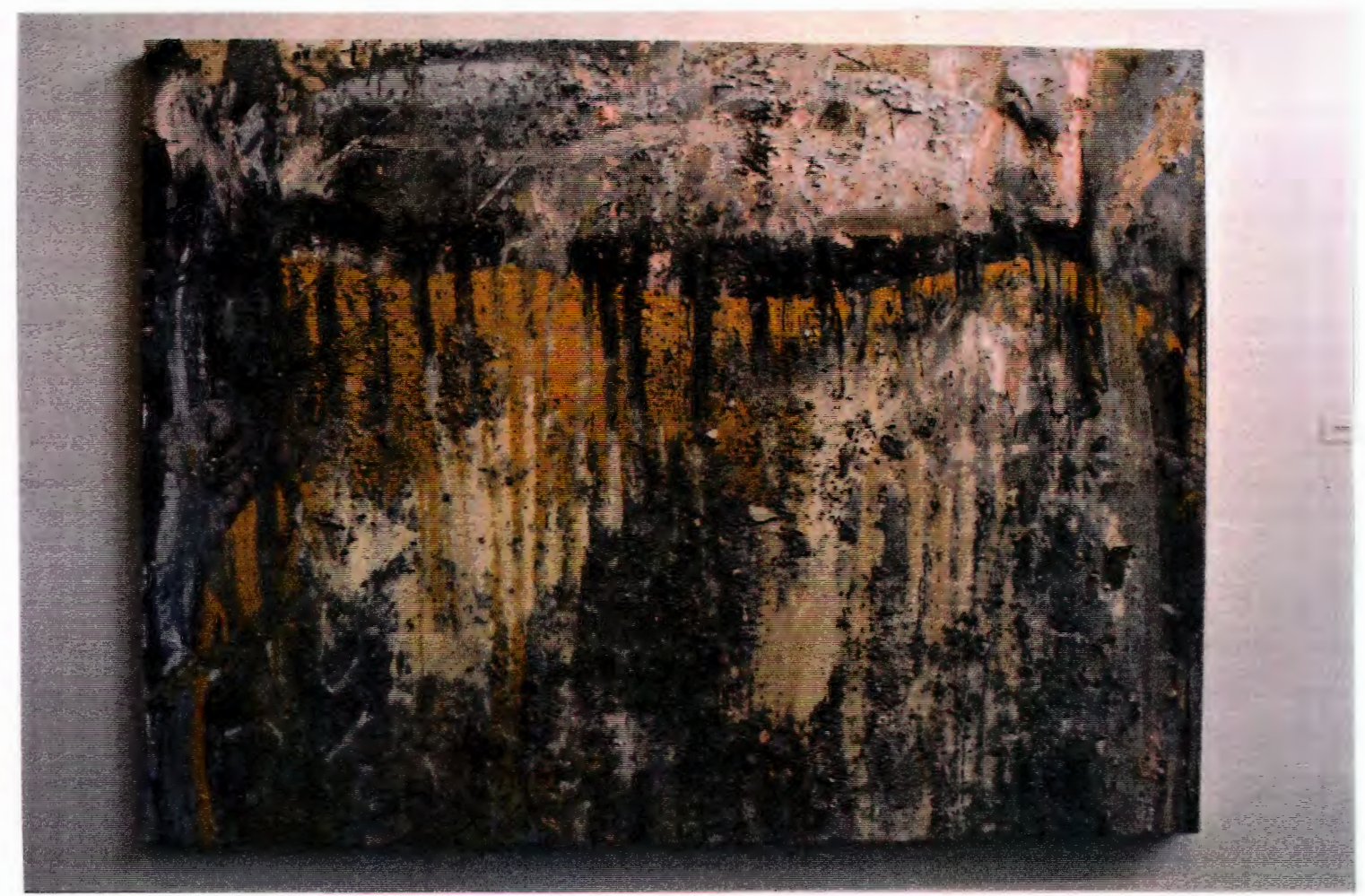

East Prussian Historical No. 2, 1997 acrylic media and plaster on board $72^{\prime \prime} \times 96^{\prime \prime}$ 


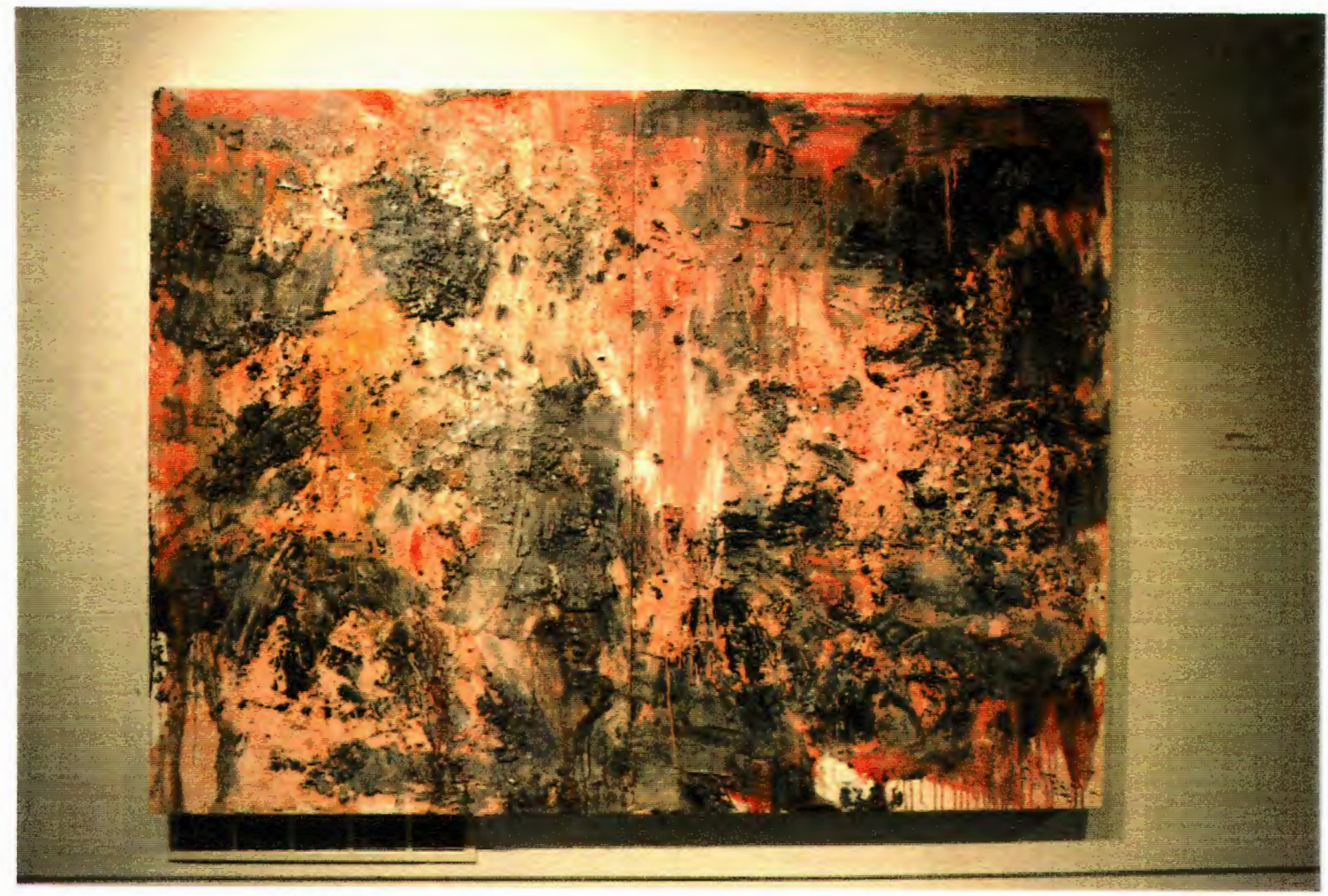

Conception, 1997

acrylic media and plaster on board

$72 "$ x 96" 


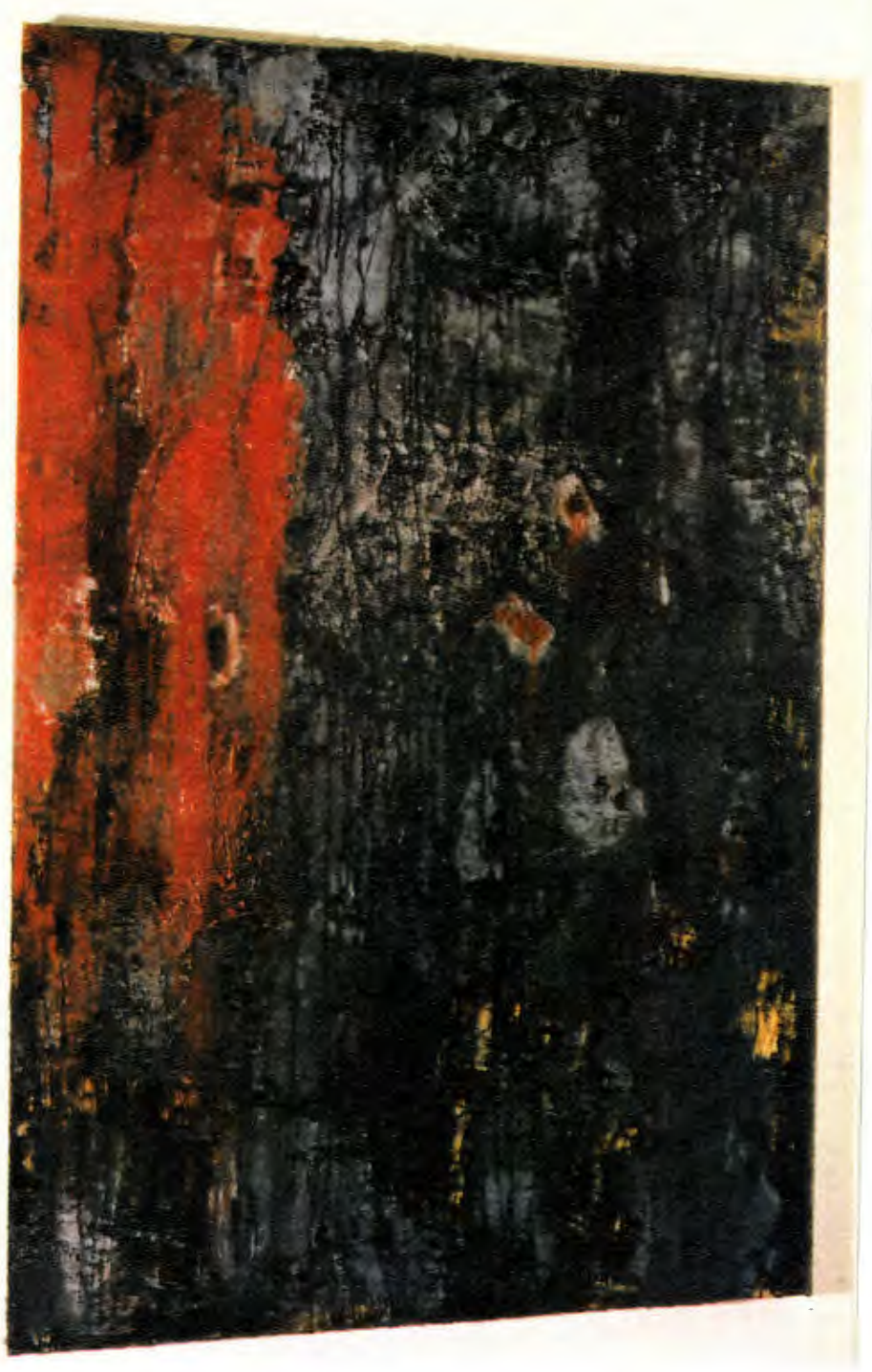

Fate and Red, 1996

acrylic media and plaster on board $72^{\prime \prime} \times 48$ "

(photographed at an angle) 


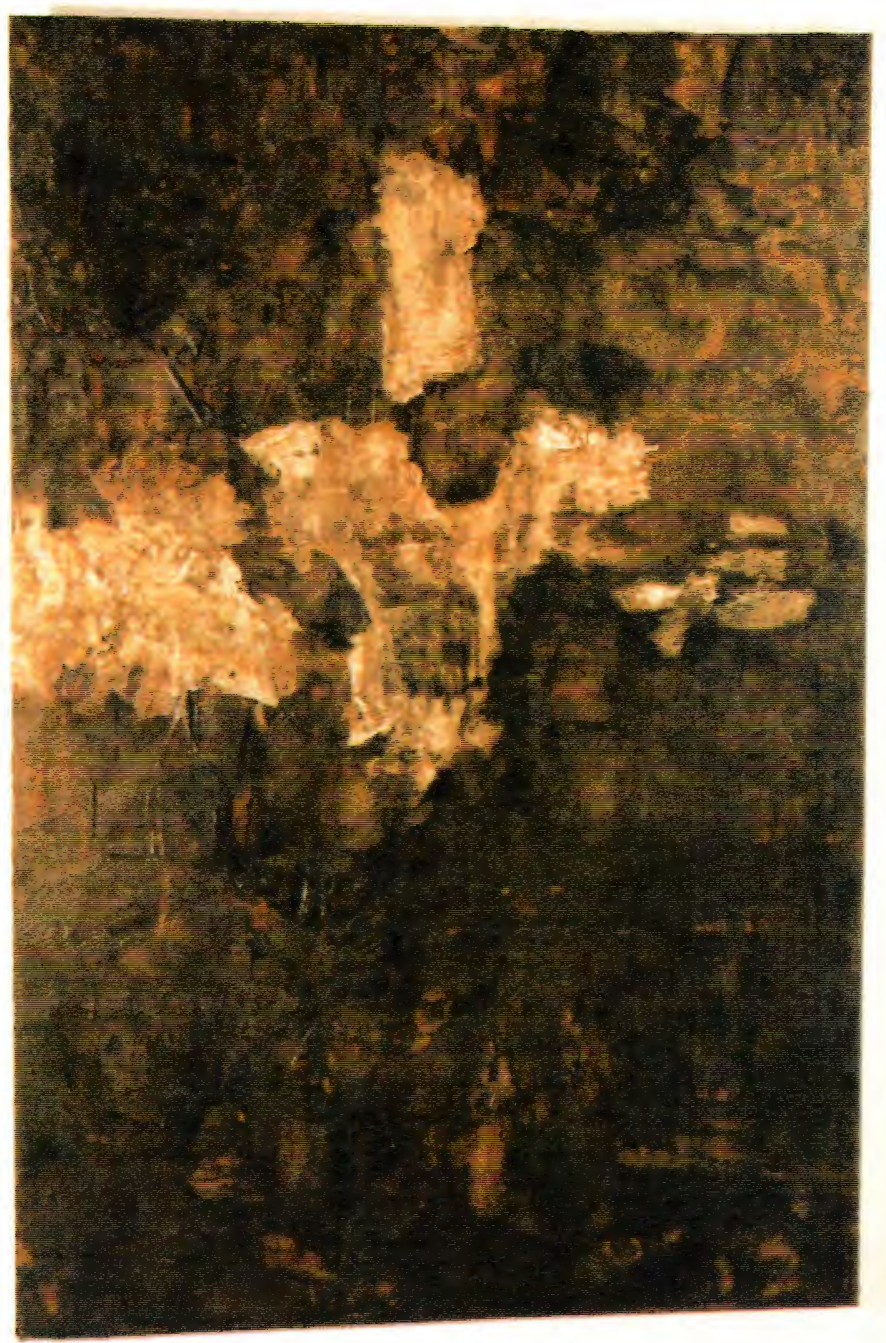

Guardian, 1996

acrylic media and plaster on board

72 " x 48"

(photographed at an angle) 


\section{References}

Hickey, David. "Nothing Like the Sun: On Robert Mappelthorpe's X Portfolio." In The Invisible Dragon: Four Essays on Beauty. Los Angeles: Art issues. Press, 1993.

Lucie-Smith, Edward. Art Today. London: Phaidon Press Limited, 1995.

Markee, Michael and Vincent Wixon. "William Stafford: The Life of a Poem." Contemporary Poets Series (video). Ashland, OR: TTTD Productions, 1992. 